Supplement of

\title{
Classification of summertime synoptic patterns in Beijing and their associations with boundary layer structure affecting aerosol pollution
}

Yucong Miao et al.

Correspondence to: Jianping Guo (jpguocams@gmail.com) and Zhanqing Li (zli@atmos.umd.edu)

The copyright of individual parts of the supplement might differ from the CC-BY 3.0 licence. 
Table S1. The identified synoptic pattern types during summer from 2011 to 2014 . The date is presented as day/month, and the synoptic type (1 to 7) is shown by the bold number with shade.

\begin{tabular}{|c|c|c|c|c|c|c|c|c|c|c|c|}
\hline \multicolumn{6}{|c|}{2011} & \multicolumn{6}{|c|}{2012} \\
\hline $1 / 6$ & 4 & $1 / 7$ & 4 & $1 / 8$ & 4 & $1 / 6$ & 5 & $1 / 7$ & 4 & $1 / 8$ & 1 \\
\hline $2 / 6$ & 4 & $2 / 7$ & 3 & $2 / 8$ & 1 & $2 / 6$ & 5 & $2 / 7$ & 3 & $2 / 8$ & 1 \\
\hline $3 / 6$ & 3 & $3 / 7$ & 7 & $3 / 8$ & 1 & $3 / 6$ & 5 & $3 / 7$ & 3 & $3 / 8$ & 1 \\
\hline $4 / 6$ & 3 & $4 / 7$ & 4 & $4 / 8$ & 1 & $4 / 6$ & 4 & $4 / 7$ & 5 & $4 / 8$ & 2 \\
\hline $5 / 6$ & 4 & $5 / 7$ & 4 & $5 / 8$ & 1 & $5 / 6$ & 4 & $5 / 7$ & 1 & $5 / 8$ & 2 \\
\hline $6 / 6$ & 4 & $6 / 7$ & 4 & $6 / 8$ & 1 & $6 / 6$ & 4 & $6 / 7$ & 1 & $6 / 8$ & 1 \\
\hline $7 / 6$ & 4 & $7 / 7$ & 4 & $7 / 8$ & 2 & $7 / 6$ & 4 & $7 / 7$ & 1 & $7 / 8$ & 4 \\
\hline $8 / 6$ & 3 & $8 / 7$ & 4 & $8 / 8$ & 7 & $8 / 6$ & 4 & $8 / 7$ & 1 & $8 / 8$ & 3 \\
\hline $9 / 6$ & 3 & $9 / 7$ & 4 & $9 / 8$ & 6 & $9 / 6$ & 4 & $9 / 7$ & 1 & $9 / 8$ & 2 \\
\hline $10 / 6$ & 5 & $10 / 7$ & 1 & $10 / 8$ & 6 & $10 / 6$ & 4 & $10 / 7$ & 7 & $10 / 8$ & 2 \\
\hline $11 / 6$ & 3 & $11 / 7$ & 1 & $11 / 8$ & 1 & $11 / 6$ & 4 & $11 / 7$ & 7 & $11 / 8$ & 2 \\
\hline $12 / 6$ & 7 & $12 / 7$ & 1 & $12 / 8$ & 5 & $12 / 6$ & 5 & $12 / 7$ & 7 & $12 / 8$ & 2 \\
\hline $13 / 6$ & 1 & $13 / 7$ & 5 & $13 / 8$ & 5 & $13 / 6$ & 5 & $13 / 7$ & 2 & $13 / 8$ & 6 \\
\hline $14 / 6$ & 5 & $14 / 7$ & 5 & $14 / 8$ & 5 & $14 / 6$ & 5 & $14 / 7$ & 2 & $14 / 8$ & 4 \\
\hline $15 / 6$ & 5 & $15 / 7$ & 5 & $15 / 8$ & 7 & $15 / 6$ & 3 & $15 / 7$ & 2 & $15 / 8$ & 3 \\
\hline $16 / 6$ & 5 & $16 / 7$ & 5 & $16 / 8$ & 7 & $16 / 6$ & 4 & $16 / 7$ & 1 & $16 / 8$ & 1 \\
\hline $17 / 6$ & 4 & $17 / 7$ & 2 & $17 / 8$ & 3 & $17 / 6$ & 5 & $17 / 7$ & 1 & $17 / 8$ & 4 \\
\hline $18 / 6$ & 1 & $18 / 7$ & 2 & $18 / 8$ & 3 & $18 / 6$ & 5 & $18 / 7$ & 1 & $18 / 8$ & 3 \\
\hline $19 / 6$ & 4 & $19 / 7$ & 2 & $19 / 8$ & 1 & $19 / 6$ & 1 & $19 / 7$ & 1 & $19 / 8$ & 1 \\
\hline $20 / 6$ & 4 & $20 / 7$ & 1 & $20 / 8$ & 1 & $20 / 6$ & 1 & $20 / 7$ & 1 & $20 / 8$ & 3 \\
\hline $21 / 6$ & 5 & $21 / 7$ & 5 & $21 / 8$ & 1 & $21 / 6$ & 1 & $21 / 7$ & 5 & $21 / 8$ & 3 \\
\hline $22 / 6$ & 5 & $22 / 7$ & 5 & $22 / 8$ & 2 & $22 / 6$ & 1 & $22 / 7$ & 3 & $22 / 8$ & 1 \\
\hline $23 / 6$ & 2 & $23 / 7$ & 1 & $23 / 8$ & 1 & $23 / 6$ & 1 & $23 / 7$ & 1 & $23 / 8$ & 1 \\
\hline $24 / 6$ & 2 & $24 / 7$ & 5 & $24 / 8$ & 1 & $24 / 6$ & 1 & $24 / 7$ & 5 & $24 / 8$ & 1 \\
\hline $25 / 6$ & 2 & $25 / 7$ & 5 & $25 / 8$ & 1 & $25 / 6$ & 1 & $25 / 7$ & 5 & $25 / 8$ & 4 \\
\hline $26 / 6$ & 2 & $26 / 7$ & 5 & $26 / 8$ & 1 & $26 / 6$ & 1 & $26 / 7$ & 4 & $26 / 8$ & 1 \\
\hline $27 / 6$ & 5 & $27 / 7$ & 5 & $27 / 8$ & 1 & $27 / 6$ & 1 & $27 / 7$ & 5 & $27 / 8$ & 1 \\
\hline $28 / 6$ & 1 & $28 / 7$ & 4 & $28 / 8$ & 1 & $28 / 6$ & 1 & $28 / 7$ & 5 & $28 / 8$ & 7 \\
\hline $29 / 6$ & 4 & $29 / 7$ & 1 & $29 / 8$ & 5 & $29 / 6$ & 3 & $29 / 7$ & 3 & $29 / 8$ & 3 \\
\hline $30 / 6$ & 5 & $30 / 7$ & 4 & $30 / 8$ & 4 & $30 / 6$ & 4 & $30 / 7$ & 6 & $30 / 8$ & 1 \\
\hline & & $31 / 7$ & 4 & $31 / 8$ & 3 & & & $31 / 7$ & 1 & $31 / 8$ & 1 \\
\hline
\end{tabular}




\begin{tabular}{|c|c|c|c|c|c|c|c|c|c|c|c|}
\hline \multicolumn{6}{|c|}{2013} & \multicolumn{6}{|c|}{2014} \\
\hline $1 / 6$ & 6 & $1 / 7$ & 5 & $1 / 8$ & 1 & $1 / 6$ & 1 & $1 / 7$ & 5 & $1 / 8$ & 2 \\
\hline $2 / 6$ & 5 & $2 / 7$ & 3 & $2 / 8$ & 1 & $2 / 6$ & 2 & $2 / 7$ & 1 & $2 / 8$ & 2 \\
\hline $3 / 6$ & 5 & $3 / 7$ & 3 & $3 / 8$ & 4 & $3 / 6$ & 2 & $3 / 7$ & 4 & $3 / 8$ & 2 \\
\hline $4 / 6$ & 1 & $4 / 7$ & 3 & $4 / 8$ & 4 & $4 / 6$ & 2 & $4 / 7$ & 1 & $4 / 8$ & 7 \\
\hline $5 / 6$ & 1 & $5 / 7$ & 3 & $5 / 8$ & 5 & $5 / 6$ & 3 & $5 / 7$ & 4 & $5 / 8$ & 3 \\
\hline $6 / 6$ & 1 & $6 / 7$ & 1 & $6 / 8$ & 1 & $6 / 6$ & 3 & $6 / 7$ & 4 & $6 / 8$ & 2 \\
\hline $7 / 6$ & 5 & $7 / 7$ & 4 & $7 / 8$ & 4 & $7 / 6$ & 7 & $7 / 7$ & 4 & $7 / 8$ & 1 \\
\hline $8 / 6$ & 4 & $8 / 7$ & 5 & $8 / 8$ & 4 & $8 / 6$ & 5 & $8 / 7$ & 3 & $8 / 8$ & 1 \\
\hline $9 / 6$ & 3 & $9 / 7$ & 5 & $9 / 8$ & 4 & $9 / 6$ & 5 & $9 / 7$ & 3 & $9 / 8$ & 1 \\
\hline $10 / 6$ & 2 & $10 / 7$ & 1 & $10 / 8$ & 5 & $10 / 6$ & 2 & $10 / 7$ & 3 & $10 / 8$ & 3 \\
\hline $11 / 6$ & 7 & $11 / 7$ & 5 & $11 / 8$ & 1 & $11 / 6$ & 7 & $11 / 7$ & 3 & $11 / 8$ & 3 \\
\hline $12 / 6$ & 1 & $12 / 7$ & 5 & $12 / 8$ & 4 & $12 / 6$ & 7 & $12 / 7$ & 3 & $12 / 8$ & 3 \\
\hline $13 / 6$ & 1 & $13 / 7$ & 5 & $13 / 8$ & 4 & $13 / 6$ & 7 & $13 / 7$ & 3 & $13 / 8$ & 4 \\
\hline $14 / 6$ & 1 & $14 / 7$ & 1 & $14 / 8$ & 4 & $14 / 6$ & 6 & $14 / 7$ & 5 & $14 / 8$ & 4 \\
\hline $15 / 6$ & 4 & $15 / 7$ & 5 & $15 / 8$ & 5 & $15 / 6$ & 5 & $15 / 7$ & 5 & $15 / 8$ & 4 \\
\hline $16 / 6$ & 4 & $16 / 7$ & 4 & $16 / 8$ & 4 & $16 / 6$ & 5 & $16 / 7$ & 5 & $16 / 8$ & 5 \\
\hline $17 / 6$ & 3 & $17 / 7$ & 1 & $17 / 8$ & 3 & $17 / 6$ & 5 & $17 / 7$ & 5 & $17 / 8$ & 1 \\
\hline $18 / 6$ & 3 & $18 / 7$ & 5 & $18 / 8$ & 3 & $18 / 6$ & 3 & $18 / 7$ & 5 & $18 / 8$ & 2 \\
\hline $19 / 6$ & 3 & $19 / 7$ & 5 & $19 / 8$ & 3 & $19 / 6$ & 1 & $19 / 7$ & 1 & $19 / 8$ & 1 \\
\hline $20 / 6$ & 2 & $20 / 7$ & 6 & $20 / 8$ & 1 & $20 / 6$ & 1 & $20 / 7$ & 4 & $20 / 8$ & 4 \\
\hline $21 / 6$ & 7 & $21 / 7$ & 1 & $21 / 8$ & 4 & $21 / 6$ & 2 & $21 / 7$ & 3 & $21 / 8$ & 1 \\
\hline $22 / 6$ & 1 & $22 / 7$ & 1 & $22 / 8$ & 3 & $22 / 6$ & 2 & $22 / 7$ & 3 & $22 / 8$ & 1 \\
\hline $23 / 6$ & 1 & $23 / 7$ & 4 & $23 / 8$ & 3 & $23 / 6$ & 6 & $23 / 7$ & 3 & $23 / 8$ & 3 \\
\hline $24 / 6$ & 1 & $24 / 7$ & 3 & $24 / 8$ & 3 & $24 / 6$ & 4 & $24 / 7$ & 2 & $24 / 8$ & 3 \\
\hline $25 / 6$ & 5 & $25 / 7$ & 6 & $25 / 8$ & 3 & $25 / 6$ & 4 & $25 / 7$ & 2 & $25 / 8$ & 3 \\
\hline $26 / 6$ & 5 & $26 / 7$ & 5 & $26 / 8$ & 6 & $26 / 6$ & 3 & $26 / 7$ & 1 & $26 / 8$ & 4 \\
\hline $27 / 6$ & 5 & $27 / 7$ & 5 & $27 / 8$ & 1 & $27 / 6$ & 7 & $27 / 7$ & 1 & $27 / 8$ & 1 \\
\hline $28 / 6$ & 5 & $28 / 7$ & 4 & $28 / 8$ & 5 & $28 / 6$ & 7 & $28 / 7$ & 4 & $28 / 8$ & 1 \\
\hline $29 / 6$ & 5 & $29 / 7$ & 4 & $29 / 8$ & 7 & $29 / 6$ & 6 & $29 / 7$ & 5 & $29 / 8$ & 1 \\
\hline $30 / 6$ & 5 & $30 / 7$ & 1 & $30 / 8$ & 3 & $30 / 6$ & 1 & $30 / 7$ & 1 & $30 / 8$ & 1 \\
\hline & & $31 / 7$ & 1 & $31 / 8$ & 3 & & & $31 / 7$ & 1 & $31 / 8$ & 2 \\
\hline
\end{tabular}


Table S2. The $\mathrm{PM}_{2.5}$ concentrations and meteorological variables of the polluted synoptic types $(1,4$, and 5$)$ and other types. Mean values \pm one standard deviation are listed. The meteorological variables include 2-m temperature (T2), 2-m relative humidity (RH2), wind speed at the $925-\mathrm{hPa}$ level (WS), southerly wind frequencies at the 925h-hPa level (WD), total cloud cover at 1400 BJT (CLD), and the BLH at 1400 BJT. The correlation coefficients $(\mathrm{R})$ between the meteorological variable and $\mathrm{PM}_{2.5}$ concentration are also given, which are calculated based on the seven pairs of mean values of each synoptic pattern.

\begin{tabular}{|c|c|c|c|}
\hline \# & $\begin{array}{l}\text { Polluted types } \\
(1,4 \text {, and } 5)\end{array}$ & $\begin{array}{c}\text { Other types } \\
(2,3,6 \text {, and } 7)\end{array}$ & $\mathbf{R}\left(\#, \mathbf{P M}_{2.5}\right)$ \\
\hline $\mathbf{P M}_{2.5}\left(\mu \mathrm{g} \mathrm{m}^{-3}\right)$ & $99.7 \pm 51.9$ & $56.8 \pm 40.2$ & / \\
\hline BLH (km) & $1.17 \pm 0.59$ & $1.63 \pm 0.69$ & $-0.97 *$ \\
\hline RH2 (\%) & $68.1 \pm 14.3$ & $59.4 \pm 14.1$ & $0.85 *$ \\
\hline CLD (\%) & $92 \pm 22$ & $74 \pm 36$ & $0.84 *$ \\
\hline 925-hPa WD (South) (\%) & $61 \pm 6$ & $49 \pm 7$ & $0.78 *$ \\
\hline $\mathrm{T} 2(\mathrm{~K})$ & $299.5 \pm 2.5$ & $299.8 \pm 2.7$ & -0.33 \\
\hline 925-hPa WS $\left(\mathrm{m} \mathrm{s}^{-1}\right)$ & $5.1 \pm 3.1$ & $4.9 \pm 3.3$ & -0.02 \\
\hline
\end{tabular}



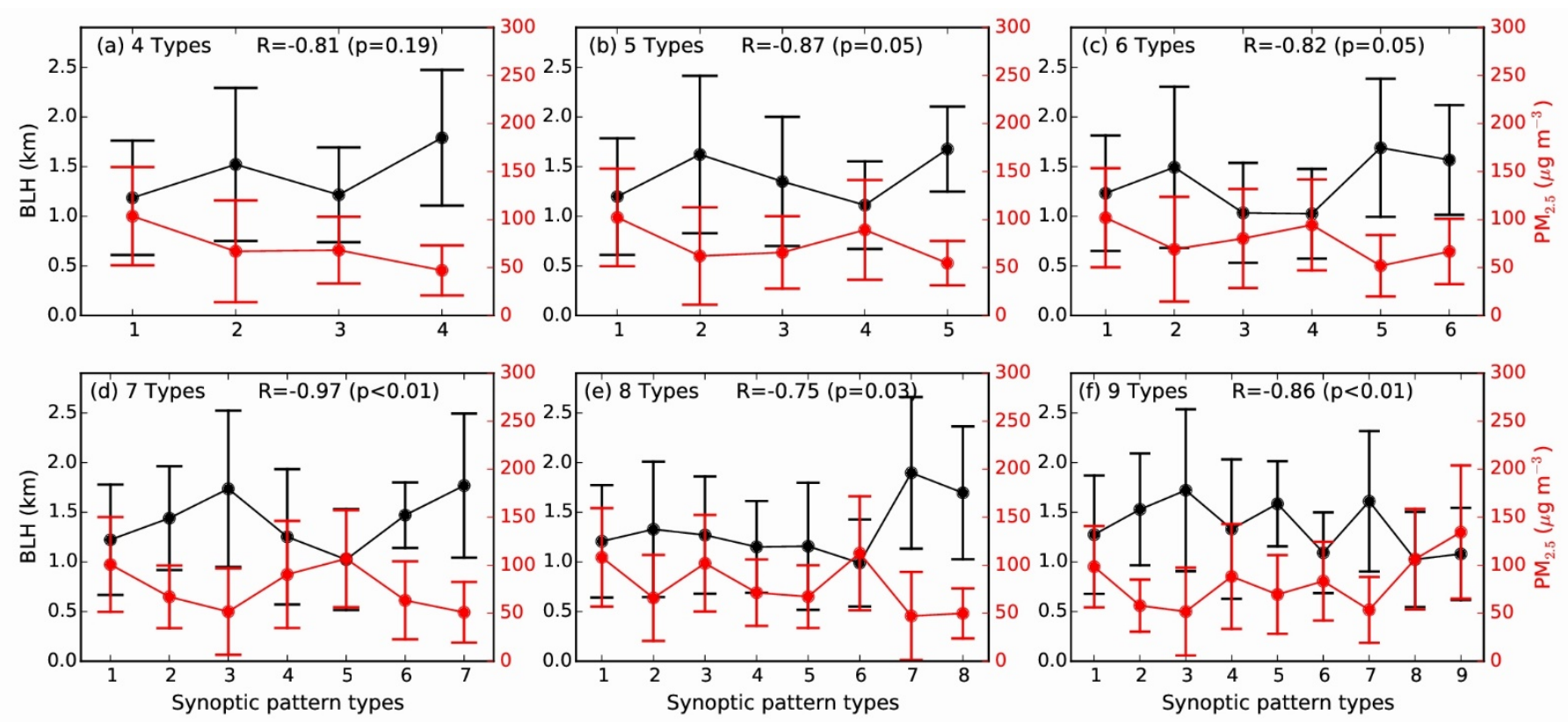

Fig. S1. Boundary layer height (BLH, in black) at 1400 BJT and daily $\mathrm{PM}_{2.5}$ concentration (in red) as a function of synoptic pattern types, which are identified using T-PCA method with (a) 4 principle components (PCs), (b) 5 PCs, (c) 6 PCs, (d) 7 PCs, (e) 8 PCs, (f) 9 PCs. Mean values \pm one standard deviation are shown. The correlation coefficient $(\mathrm{R})$ between the averaged $\mathrm{BLH}$ and $\mathrm{PM}_{2.5}$ concentration of different synoptic patterns for each panel is also given. 

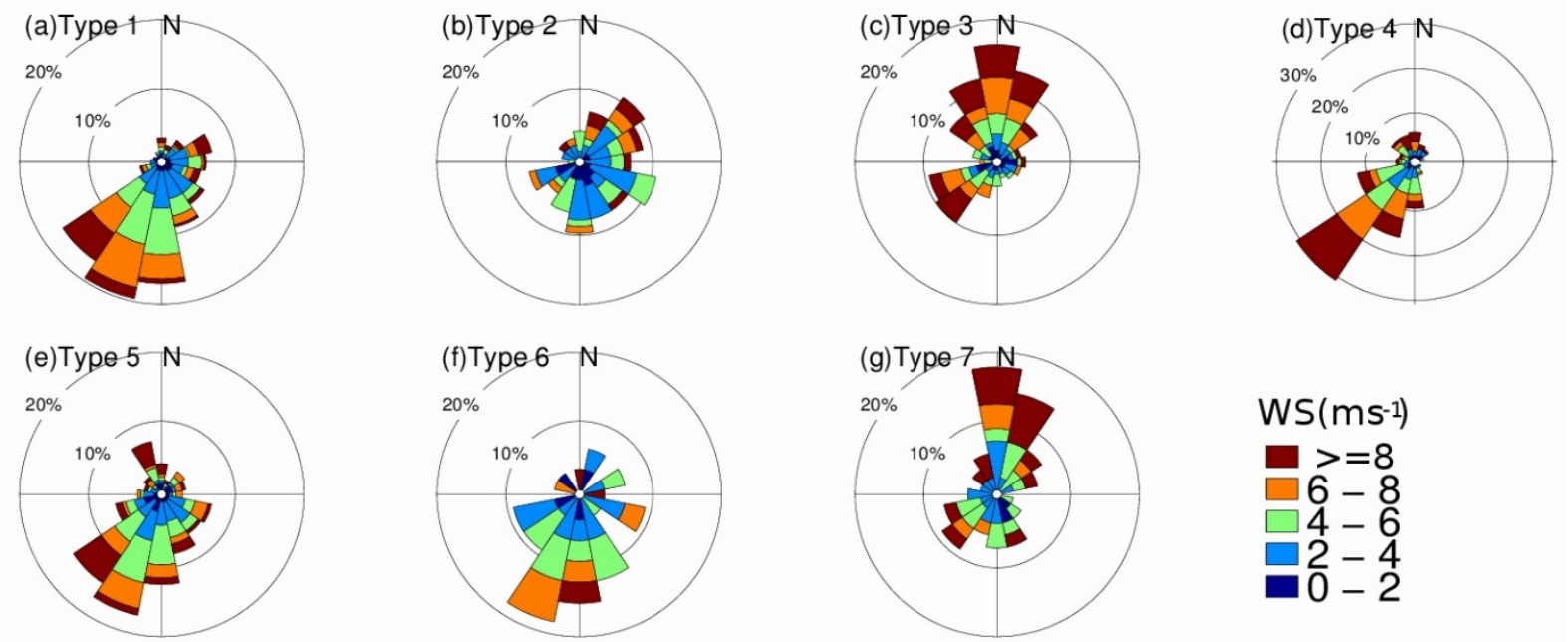

Fig. S2. The 925-hPa wind rose diagrams associated with different synoptic types.

The 925-hPa wind speed (WS) and wind direction were derived from the summertime soundings from 2011 to 2014 in Beijing. 

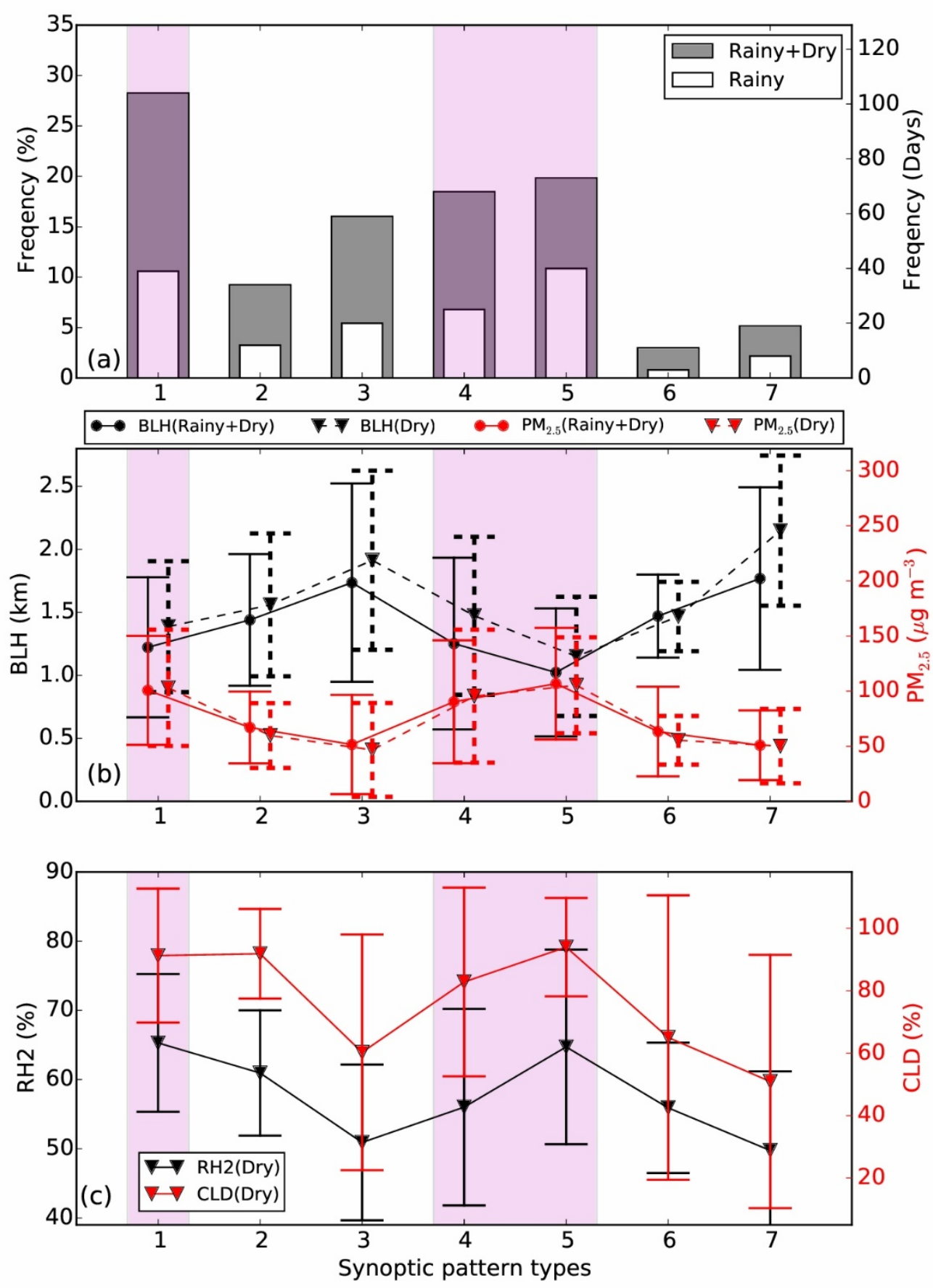

Fig. S3. (a) The occurrence frequency, (b) boundary layer height (BLH) at 1400 BJT and daily $\mathrm{PM}_{2.5}$ concentration, (c) daily 2-m relative humidity (RH2) and total cloud cover (CLD) at $1400 \mathrm{BJT}$ of different synoptic patterns derived from the summertime observations from in Beijing (39.80 $\left.{ }^{\circ} \mathrm{N}, 116.47{ }^{\circ} \mathrm{E}\right)$ from 2011 to 2014 . The corresponding values excluded observations of rainy days (Dry) are also illustrated in (b) and (c). The pink shades mark the three synoptic patterns have relatively severe aerosol pollution, including the Type 1, Type 4, and Type 5. 


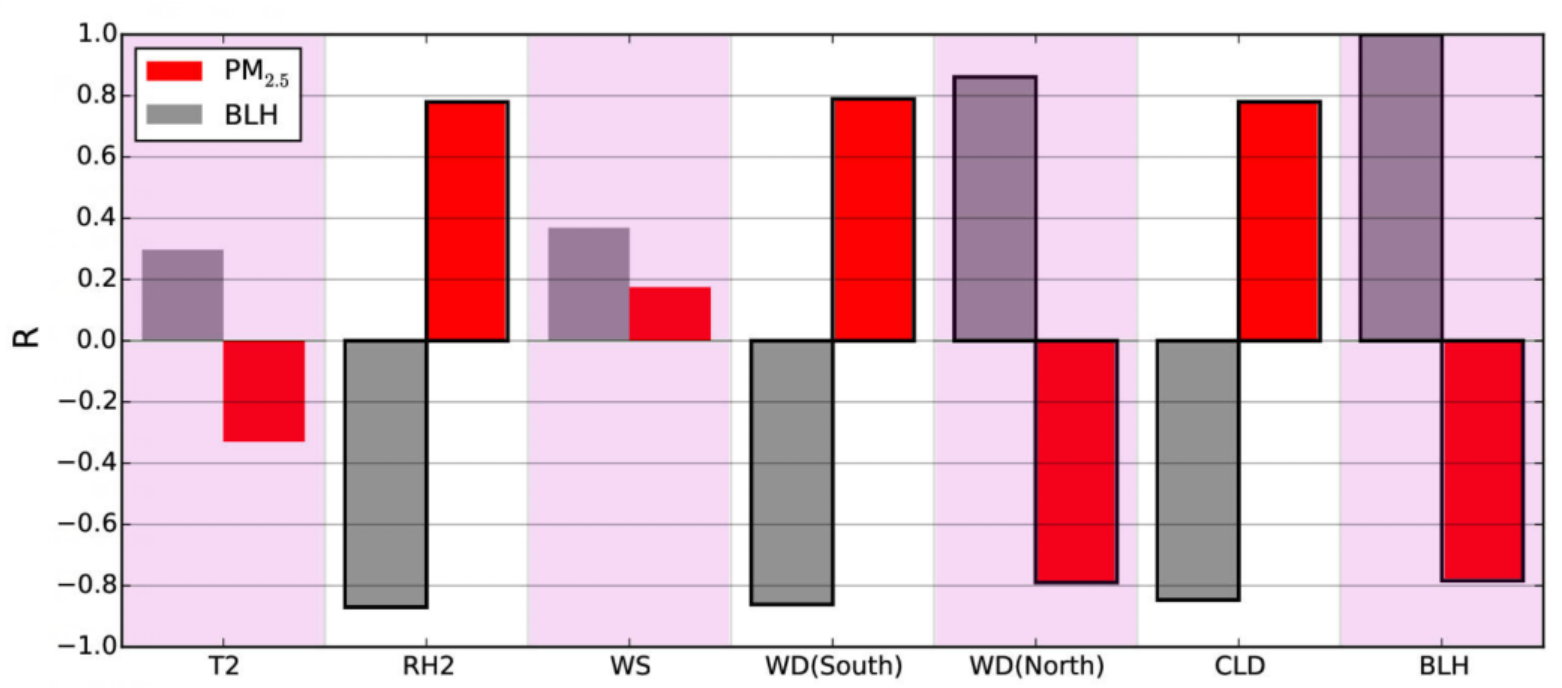

Fig. S4. Correlations (R) between the mean values of $\mathrm{PM}_{2.5}$ concentration and meteorological parameters for the different synoptic patterns, including (from left to right) 2-m temperature (T2), 2-m relative humidity (RH2), wind speed at the $925-\mathrm{hPa}$ level (WS), south- and north- wind frequencies at the 925h-hPa level (WD), total cloud cover at 1400 BJT (CLD), and the BLH at 1400 BJT. The grey bars represent the correlations between BLH and these meteorological parameters. Bars outlined in thick black lines indicate correlation coefficients $(\mathrm{R})$ that are statistically significant $(\mathrm{p}<0.05)$. Note that the observations of rainy days are not considered. 


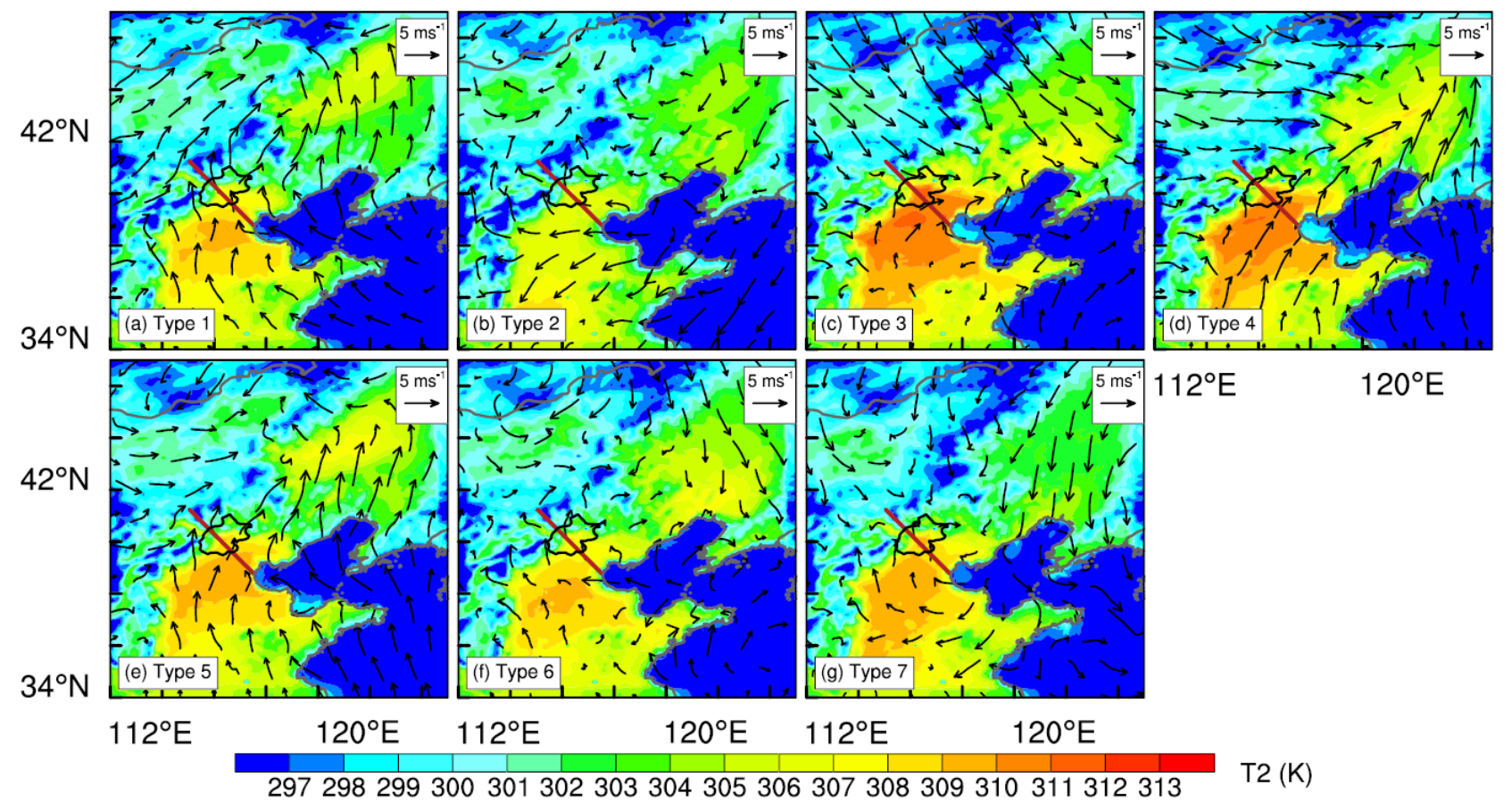

Fig. S5. Spatial distributions of simulated 2-m temperature (T2) and 10-m wind vectors at 1400 BJT for the seven synoptic pattern types: (a) Type 1, (b) Type 2, (c) Type 3, (d) Type 4, (e) Type 5, (f) Type 6, and (g) Type 7. The location of the Beijing metropolitan area is outlined in black near the center of each panel. 


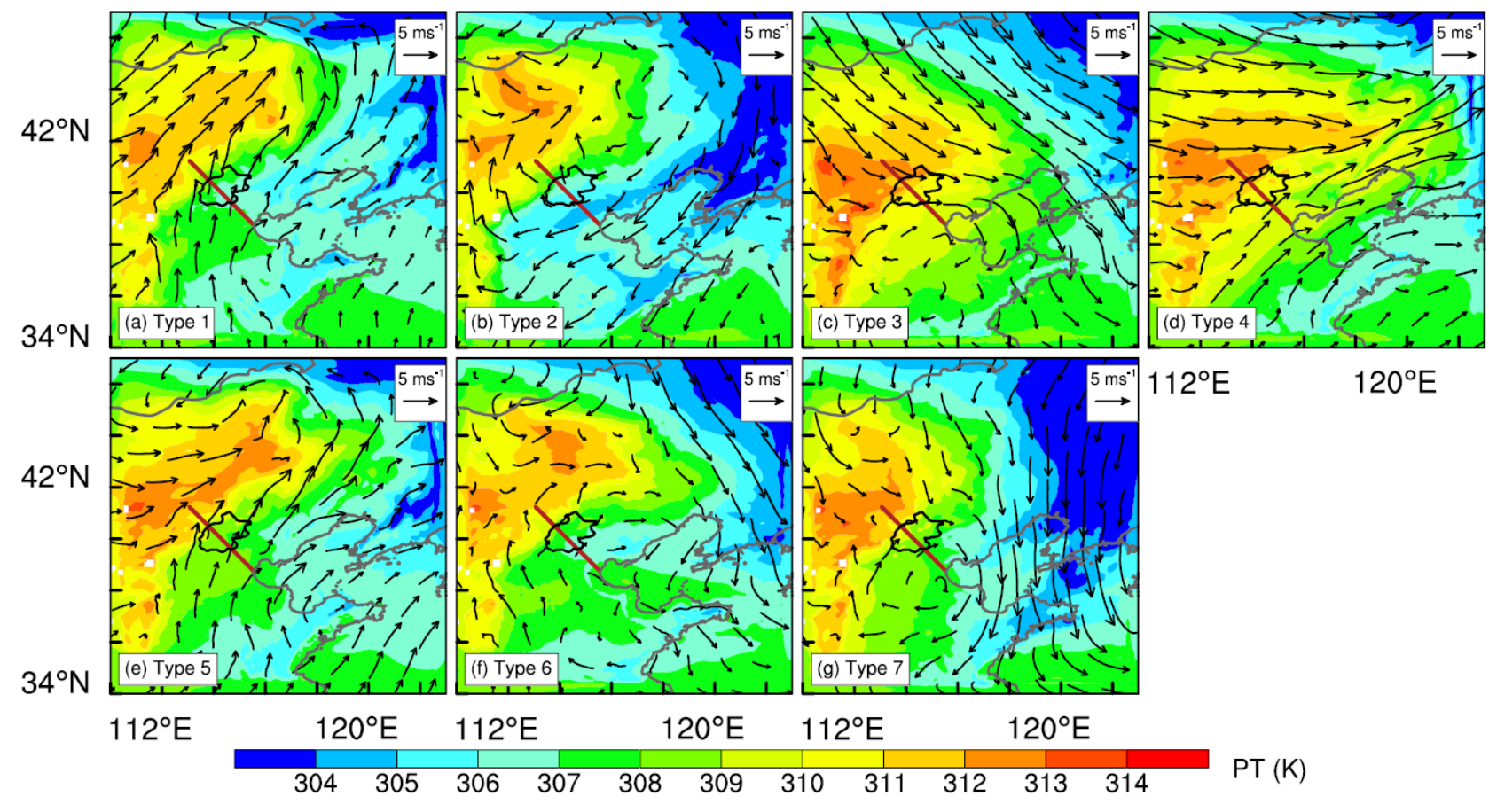

Fig. S6. Similar as Fig. S5, but for the spatial distributions of simulated $800-\mathrm{hPa}$ PT and wind vectors at 1400 BJT for the seven synoptic pattern types: (a) Type 1, (b) Type 2, (c) Type 3, (d) Type 4, (e) Type 5, (f) Type 6, and (g) Type 7. 